\title{
Should buttresses and sealants be used to manage pulmonary parenchymal air leaks?
}

\author{
Sunil Singhal, MD, ${ }^{\mathrm{a}}$ and Joseph B. Shrager, $\mathrm{MD}^{\mathrm{b}}$
}

\begin{abstract}
Although the vast majority of air leaks after pulmonary resection are of no major significance and resolve spontaneously after a day or so, some air leaks will persist. These prolonged air leaks, and the initial air leaks that lead to them, have drawn substantial attention for a variety of reasons. First, air leaks are associated with (and may cause) other cardiopulmonary complications, thereby increasing the overall morbidity associated with pulmonary resection. Second, even in the absence of associated complications, an air leak that lasts after a patient is otherwise ready for discharge may prolong hospital stay, creating a substantial economic impact.
\end{abstract}

Both industry and independent investigators have proposed a variety of solutions to the problem of air leaks. We and other coauthors recently reviewed the postoperative techniques that might be used to reduce the duration of air leaks and made suggestions regarding the use of these techniques. ${ }^{1}$ A number of equally controversial intraoperative products and maneuvers have been advocated to prevent or ameliorate air leaks. These potential solutions include a variety of glues and sealants designed to be applied to areas of leakage, buttressing materials for staple lines, and finally some traditional surgical techniques. Multiple studies, including quite a few randomized clinical trials, have been published in recent years to evaluate these products and techniques.

Several issues, however, complicate the thought process when deciding whether to use these products and techniques. First, the data that have accumulated regarding their effectiveness are often conflicting. Results that statistically favor the use of a product may not demonstrate a sufficient magnitude of benefit for clinical relevance. Second, the data suffer from broader problems, such as the frequent failure to report on the outcome variable of most concern to surgeons - the incidence of prolonged or complicated air leak-and the general failure to focus study on high-risk groups (eg, patients with emphysema). Finally, although

\footnotetext{
From the Division of Thoracic Surgery, ${ }^{a}$ Department of Surgery, University of Pennsylvania School of Medicine, Philadelphia, Pa; and the Division of Thoracic Surgery, ${ }^{\mathrm{b}}$ Department of Cardiothoracic Surgery, Stanford University School of Medicine, and Palo Alto Veterans Affairs Health Care System, Palo Alto, Calif. Disclosures: None.

Received for publication Dec 16, 2009; revisions received Jun 2, 2010; accepted for publication Jun 28, 2010; available ahead of print Oct 18, 2010.

Address for reprints: Sunil Singhal, MD, University of Pennsylvania School of Medicine, Surgery, 3400 Spruce St, 6 Silverstein Pavilion, Philadelphia, PA 19104 (E-mail: sunil.singhal@uphs.upenn.edu).

J Thorac Cardiovasc Surg 2010;140:1220-5 0022-5223/\$0.00

Published by Elsevier Inc. on behalf of The American Association for Thoracic Surgery

doi:10.1016/j.jtcvs.2010.06.039
}

commercial products to manage air leak add substantially to the cost of an operation, few studies have reported on their cost-effectiveness. Certainly, use of an expensive product with marginal evidence of its effectiveness is in no one's best interest.

As a result of the controversy in this area, we embarked on a review of the available literature. We sought to identify, read, and evaluate all publications that address the 2 most commonly used techniques in intraoperative air leak management: sealants and buttresses. This commentary and our management suggestions (Table 1) are based on that review and, to a lesser extent, on our personal experience.

We specifically focus here on air leaks arising from the lung parenchyma-not bronchial dehiscence, for which management is generally quite different. We define air leak as any leakage of air from the lung that is detected as a result of bubbles in a chest drainage system, progressive subcutaneous emphysema, or an expanding pneumothorax.

\section{BACKGROUND}

\section{Clinical Impact of Air Leaks}

Several studies have demonstrated an association between postoperative air leak and increased complications after lobectomy. Brunelli and colleagues ${ }^{2}$ found that patients with prolonged air leak had a dramatically greater rate of empyema. Varela and associates ${ }^{3}$ found that prolonged air leak was associated with greater pulmonary morbidity, including atelectasis, pneumonia, and empyema. Okereke and colleagues ${ }^{4}$ found that any air leak at all was associated with more complications, as did DeCamp and coworkers ${ }^{5}$ for patients after lung volume reduction surgery (LVRS).

It has also been clearly demonstrated in multiple studies that air leak increases both hospital stay and cost. Every study in the routine lung resection population reporting hospital stay or cost as a function of air leak has found a clear association. ${ }^{2-4,6,7}$ These studies have found that air leak prolongs hospital stay by between 4 and 13.1 days. In a study of post-LVRS patients, ${ }^{5}$ mean hospital stay with air leak was 11.8 days, versus 7.6 days without air leak $(P=.0005)$.

\section{Preoperative Risk Factors for Air Leaks}

The most consistently identified risk factor for air leak is chronic obstructive pulmonary disease (COPD). Many pulmonary function test parameters that reflect severity of COPD are associated with air leak, including reduced forced expiratory volume in 1 second $\left(\mathrm{FEV}_{1}\right),{ }^{6,8,9}$ both $\mathrm{FEV}_{1}$ and ratio of $\mathrm{FEV}_{1}$ to forced vital capacity less than $70 \% .{ }^{10}$ and ratio of $\mathrm{FEV}_{1}$ to forced vital capacity less than $50 \%$. $^{11}$ 


\section{Abbreviations and Acronyms}

COPD $=$ chronic obstructive pulmonary disease

$\mathrm{FEV}_{1}=$ forced expiratory volume in 1 second

LVRS $=$ lung volume reduction surgery

Patients undergoing LVRS for severe emphysema are especially susceptible to air leak, ${ }^{5}$ as are those undergoing other types of resection with $\mathrm{FEV}_{1}$ less than $35 \%$ of the predicted value. ${ }^{12}$ It is our opinion that patients with COPD with predominant emphysema (bullous disease, fragile lung tissue) are at greater risk for prolonged air leak than are those with predominant chronic bronchitis.

Other risk factors convincingly associated with air leak include the presence of adhesions, ${ }^{8}$ upper lobectomy and bilobectomy versus other lobectomies, ${ }^{8}$ lobectomy versus lesser resections, ${ }^{9}$ and steroid use greater than $10 \mathrm{mg}$ daily for longer than 1 month. ${ }^{9}$ The incidence of air leak is likely surgeon dependent, ${ }^{4}$ and larger air leaks clearly carry a greater risk of becoming prolonged air leaks. ${ }^{9}$ In the post-LVRS population, ${ }^{5}$ risk factors for air leaks were found to be similar to those after standard pulmonary resection, including severity of emphysema, adhesions, and steroid use (inhaled). In the quite different population of intubated patients undergoing lung biopsy for adult respiratory distress syndrome, the only multivariate predictor of air leak was peak airway pressure. The risk of air leak was reduced by $42 \%$ for every $5-\mathrm{cm}$ $\mathrm{H}_{2} \mathrm{O}$ reduction in peak airway pressure. ${ }^{13}$

\section{THE EVIDENCE FOR STAPLE LINE BUTTRESSES}

In the belief that many air leaks occur at and immediately adjacent to the holes created by staples in lung tissue, Cooper and colleagues ${ }^{14}$ first reported the use of bovine pericardium to buttress staple lines during LVRS. Subsequently, this technique has been extended to relatively less emphysematous patients undergoing pulmonary resection. ${ }^{15}$ Several other materials have also been used as buttresses, including parietal pleura, polydioxane ribbon, polytetrafluoroethylene felt, expanded polytetrafluoroethylene, and collagen patches. Nonabsorbable materials carry the risk of inducing granulomatous inflammation and bacterial colonization, which has led to rare cases of metalloptysis, largely with bovine pericardium. ${ }^{16-18}$

Four randomized studies have compared buttressed to nonbuttressed stapling: 2 in the post-LVRS setting ${ }^{19,20}$ and 2 among unselected patients after lobectomy. ${ }^{21,22} \mathrm{We}$ briefly review these reports.

\section{Pulmonary Resection in Patients Without Severe Emphysema}

In studies of patients undergoing routine lobectomy $\left(\mathrm{FEV}_{1} \quad 70 \%-80 \%\right.$ predicted), Venuta and associates ${ }^{22}$ $(\mathrm{n}=30)$ demonstrated decreased air leak and shorter hospital stay with pericardial buttressing, whereas Miller and coworkers $^{21}(\mathrm{n}=80)$ demonstrated reduced duration of air leak $(P=.02)$ but no significant difference in hospital stay $(P=.24)$. The trial of Venuta and associates ${ }^{22}$ was very small and lacked the ideal control group with unbuttressed gastrointestinal anastomosis stapler use. Although both studies implied that buttressing slightly reduced duration of air leak, the larger and better-controlled trial did not identify a clear-cut benefit of in terms of either hospital stay or chest tube duration. Buttressing staples lines does add as much as several hundred dollars to procedural costs. In light of the increased costs and unclear benefits, we believe that buttressing staple lines is not recommended for the routine case of a patient with less than moderate emphysema.

\section{Pulmonary Resection in Patients With Severe Emphysema}

Management of air leak is particularly challenging in patients after LVRS. Although analysis of the National Emphysema Treatment Trial data identified no benefit to buttressing staple lines, ${ }^{5}$ this analysis was not randomized on the basis of buttressing. Other groups, with randomized study designs, have observed a benefit to reinforcing the staple line in patients undergoing LVRS for emphysema.

Two randomized trials in this high-risk population have demonstrated a benefit from buttressing staple lines with bovine pericardium. ${ }^{19,20}$ A 2-center study by Hazelrigg and colleagues ${ }^{19}$ involving 123 patients undergoing unilateral thoracoscopic LVRS showed significant decreases both in the duration of postoperative air leak, chest drainage and in hospital stay. ${ }^{19}$ Patients with buttressing had chest drains removed 2.5 days sooner and were discharged from the hospital 2.8 days sooner. Total hospital charges were similar, because costs for the pericardial sleeves offset the savings in hospital time.

A 3-center study by Stammberger and associates ${ }^{20}$ evaluating bilateral thoracoscopic LVRS $(n=65)$ showed significant decreases in the incidence of initial air leak $(77 \%$ vs $39 \%$ ), median duration of air leak ( 0 vs 4 days, $P<.001$ ), and median drainage time (5 vs 7.5 days, $P=.045$ ). Hospital stay was slightly but not statistically significantly shorter in the group with buttressing (9.5 vs 12.0 days, $P=.14$ ).

In conclusion, the evidence from limited randomized studies suggests that using buttresses on staple lines in patients with emphysema undergoing nonanatomic pulmonary resections, such as LVRS, reduces both the incidence and the duration of air leak. This permits the earlier removal of chest drains and likely shortens hospital stay. It is not clear, however, that complicated, prolonged air leaks are reduced by these buttresses, and no cost benefit of using buttressed staple lines has been demonstrated, even in this high-risk population. A decrease in the costs of the buttresses could ultimately provide a cost advantage. 
TABLE 1. Suggestions for intraoperative use of buttresses and sealants

\begin{tabular}{|c|c|c|}
\hline Class & Recommendation & Level of evidenc \\
\hline \multicolumn{3}{|c|}{ Use of staple line buttresses } \\
\hline I & $\begin{array}{l}\text { In performing lung volume reduction } \\
\text { surgery, buttressing staple lines is } \\
\text { recommended to prevent postoperative } \\
\text { air leaks. }\end{array}$ & B \\
\hline IIa & $\begin{array}{l}\text { In performing anatomic pulmonary } \\
\text { resections in patients with severe } \\
\text { emphysema (forced expiratory volume in } \\
1 \text { second } \leq 50 \% \text { predicted or gross } \\
\text { parenchymal destruction), it is } \\
\text { reasonable to buttress staple lines, but the } \\
\text { benefit remains unproven. }\end{array}$ & B \\
\hline III & $\begin{array}{l}\text { In performing pulmonary resection in } \\
\text { patients with less than severe } \\
\text { emphysema, buttressing staple lines to } \\
\text { prevent postoperative air leaks is not well } \\
\text { established and, given the increased costs } \\
\text { of therapy, should be avoided. }\end{array}$ & B \\
\hline \multicolumn{3}{|c|}{ Use of topical sealants } \\
\hline $\mathrm{IIb}$ & $\begin{array}{l}\text { Although incompletely evaluated in high- } \\
\text { risk subgroups, the use of topical sealants } \\
\text { has not consistently translated into } \\
\text { a shorter chest tube duration or stay. } \\
\text { Because the overall benefit of these } \\
\text { materials has not been demonstrated, } \\
\text { they should not be used on a routine } \\
\text { basis. }\end{array}$ & A \\
\hline
\end{tabular}

Classification of recommendations and quality of evidence are according to Sackett and colleagues ${ }^{43}$ and the American College of Cardiology and American Heart Association Task Force for Practice Guidelines. ${ }^{44}$

There are not sufficient data to provide a strong recommendation regarding the use of staple line buttresses when performing anatomic lobectomy or segmentectomy, even in patients with severe emphysema. We believe, however, that the benefit of buttressing staple lines in patients with severe emphysema likely translates to situations in which a surgeon is stapling incomplete interlobar fissures or intersegmental planes during lobectomy or segmentectomy.

\section{THE EVIDENCE FOR TOPICAL SEALANTS}

A variety of sealants have been developed in an effort to solve the problem of air leak. These topical sealants are designed to be applied over staple lines and other lung surfaces with violation of the visceral pleura. Surgical sealants appear, from the many studies that have described their application, to be successful in reducing the percentage of patients with a visible air leak at the conclusion of an operation. Studies have not, however, consistently shown that sealants substantially reduce (1) duration of air leak, (2) time to removal of chest drains, or (3) hospital stay (Table 2).

Belda-Sanchís and colleagues ${ }^{23}$ and Tambiah and colleagues ${ }^{24}$ performed comprehensive reviews of the literature evaluating sealants during pulmonary resection in patients with lung cancer. Typically, standard closure techniques plus a sealant were compared with the same intervention without a sealant. The 2010 report from Belda-Sanchís and colleagues ${ }^{23}$ identified 12 randomized, controlled trials with a total of 1097 patients. ${ }^{25-36}$ The 2007 review by Tambiah and colleagues ${ }^{24}$ added 1 more study to that analysis. ${ }^{37}$ Several additional studies ${ }^{38-42}$ have been published in this area since these 2 reviews.

These studies have described a variety of types of sealants, ranging from fibrin- and thrombin-based products to synthetic polymers and from sprays to gelatinous solutions to moistened patches. There is a broad range in quality and methodology among these trials. For example, in most cases there was no standard definition of air leak, and no attempt was made to quantify the degree of air leak in the perioperative period. In 3 trials, patients were randomly assigned to treatment after checking for the presence of intraoperative air leak, whereas in 9 trials glue was applied regardless of the presence of air leak. These studies also present few data that address costs.

Although 11 trials found that a significantly lower percentage of patients had air leak at the conclusion of the operation when sealants were used, ${ }^{25-27,29-33,36,37,40}$ most of these trials did not demonstrate any reduction in the time of chest drainage. The limiting factor in removing chest drains in these patients was often the volume of fluid drainage, rather than the presence of air leak. There were 4 exceptions to this general result. ${ }^{27,37,41,42}$ Similarly, although there was a trend in most of the publications toward a shortened hospital stay in the sealant group, only 3 studies demonstrate a significant reduction in hospital stay $^{25,37,42}: 1$ with a polymeric sealant (U.S. Patent No. 5583114), ${ }^{25} 1$ with TachoSil (Nycomed International Management GmbH, Zurich, Switzerland),${ }^{42}$ and 1 with BioGlue (CryoLife Inc, Kennesaw, Ga). ${ }^{37}$

Among patients with a postoperative air leak, regardless of whether a surgical sealant had been used, there were reductions in mean air leak duration in 4 of the trials. ${ }^{25,27,32,40}$ Interestingly, in Fabian and associates' trial, ${ }^{27}$ the incidence of prolonged air leak heavily favored sealants ( $2 \%$ vs $16 \%$, $P=.015)$. This important outcome measure was not, however, reported for most trials.

None of the previously mentioned randomized studies included subgroup analysis to evaluate the effectiveness of sealants for air leaks of varying sizes. Similarly, none of the studies were targeted at the patients at highest risk for complicated or prolonged air leaks - those with advanced emphysema - nor did any report results for subgroups of patients with substantial emphysema. There are therefore insufficient data available to determine whether there are specific subgroups of patients who would more clearly benefit from the use of sealants. One small, randomized study of sealants in patients with severe emphysema-but in the 
TABLE 2. Randomized, controlled trials evaluating surgical sealants for intraoperative air leaks

\begin{tabular}{|c|c|c|c|c|c|c|}
\hline \multirow[b]{2}{*}{ Reference } & \multirow[b]{2}{*}{ Sealant } & \multirow[b]{2}{*}{ No. } & \multicolumn{4}{|c|}{ Comparisons (treatment vs control) } \\
\hline & & & $\begin{array}{l}\text { With postoperative } \\
\text { air leaks }(\%)\end{array}$ & $\begin{array}{c}\text { Mean air leak } \\
\text { duration (d) }\end{array}$ & $\begin{array}{c}\text { Mean chest } \\
\text { drain duration }(d)\end{array}$ & $\begin{array}{c}\text { Mean hospital } \\
\text { stay (d) } \\
\end{array}$ \\
\hline Allen et $\mathrm{al}^{25}$ & $\begin{array}{l}\text { U.S. Patent No. } 5583114 \\
\text { (novel polymeric sealant) }\end{array}$ & 148 & $77 \%$ vs $16 \%$ & [2 vs 2] & [6.8 vs 6.2$]$ & 6 vs 7 \\
\hline Belboul et $\mathrm{al}^{26}$ & $\begin{array}{l}\text { Vivostat (autologous } \\
\text { fibrin sealant) }\end{array}$ & 40 & $20 \%$ vs $60 \%$ & NA & [1 vs 3] & [4 vs 4.5$]$ \\
\hline Fabian et $\mathrm{al}^{27}$ & Fibrin glue & 100 & $34 \%$ vs $68 \%$ & 1.1 vs 3.1 & 3.5 vs 5 & [4.6 vs 4.9] \\
\hline Fleisher et $\mathrm{al}^{28}$ & Fibrin glue & 28 & NA & [3.2 vs 3.3] & [6.1 vs 5.9] & [9.8 vs 11.5$]$ \\
\hline Lang et $\mathrm{al}^{29}$ & $\begin{array}{l}\text { TachoComb } \\
\text { (fleece-bound sealant) }\end{array}$ & 189 & $34 \%$ vs $37 \%$ & [1.7 vs 2$]$ & NA & NA \\
\hline Macchiarini et $\mathrm{al}^{30}$ & Focal, Inc (fibrin glue) & 26 & $0 \%$ vs $82 \%$ & [1.9 vs 2.4$]$ & [6.1 vs 6.4$]$ & [13 vs 14$]$ \\
\hline Moser et $\mathrm{al}^{41}$ & Vivostat (fibrin glue) & 25 (bilateral) & NA & NA & 2.8 vs 5.9 & NA \\
\hline Mouritzen et al ${ }^{31}$ & Fibrin glue & 114 & $39 \%$ vs $66 \%$ & [4 vs 5] & [3 vs 4$]$ & [9 vs 10$]$ \\
\hline Porte et $\mathrm{al}^{32}$ & Advaseal (polymeric sealant) & 120 & Data not provided* & 1.4 vs 2.6 & NA & [9.2 vs 8.6$]$ \\
\hline Tansley et $\mathrm{al}^{37}$ & BioGlue & 52 & 53 vs $96 \%$ & 1 vs 4 & 4 vs 5 & 6 vs 7 \\
\hline Wain et $\mathrm{al}^{33}$ & $\begin{array}{l}\text { Focal Seal (polyethylene } \\
\text { glycol-based gel) }\end{array}$ & 172 & $8 \%$ vs $71 \%$ & 1.3 vs 2.2 & [4.5 vs 5.2$]$ & [7.4 vs 10.1] \\
\hline Wong and Goldstraw ${ }^{34}$ & Tisseal (fibrin glue) & 66 & NA & [5 vs 4$]$ & [6 vs 6$]$ & [8 vs 9] \\
\hline Wurtz et al ${ }^{35}$ & Fibrin glue & 50 & $*$ & NA & NA & [11.4 vs 13$]$ \\
\hline Wurtz et $\mathrm{al}^{36}$ & Fibrin glue & 50 & $*$ & NA & NA & [9.9 vs 10.6$]$ \\
\hline Anegg et $\mathrm{al}^{42}$ & $\begin{array}{l}\text { Tachosil (fleece-bound } \\
\text { sealing) }\end{array}$ & 173 & NA & Data not provided* & 5.1 vs 6.3 & 6.2 vs 7.7 \\
\hline $\mathrm{D}^{\prime}$ Andrilli et $\mathrm{al}^{40}$ & Polymeric sealant & 203 & $15 \%$ vs $41 \%$ & 3.5 vs 4.2 & NA & [5.7 vs 6.2$]$ \\
\hline
\end{tabular}

setting of LVRS—-has been published. In this study of 25 patients undergoing bilateral thoracoscopic LVRS, autologous fibrin sealant was applied to the staple line on 1 side of the chest only. ${ }^{41}$ Both the incidence of prolonged air leak and mean duration of drainage were significantly reduced on the sealant side $(4.5 \%$ and 2.8 days vs $31.8 \%$ and 5.9 days, respectively).

There have been recent reports that a particular type of sealant combined with electrocautery dissection of fissures may be superior to the use of stapler devices. A randomized trial of 60 patients with $\mathrm{COPD}\left(\mathrm{FEV}_{1} \leq 65 \%\right)$ reported that collagen patches coated with human fibrinogen and thrombin (TachoSil) after electrocautery dissection reduced duration of chest tube drainage ( 3.5 vs 5.9 days, $P=.0021$ ) and hospital stay (5.9 vs 7.5 days, $P=.01$ ) relative to stapling. ${ }^{39} \mathrm{In}$ another study with 40 randomly assigned patients, there was a reduction in the duration of air leak in the electrocautery plus patch group ( 1.7 vs 4.5 days, $P=.003$ ). This relatively new concept of using electrocautery dissection plus sealants might even provide a cost benefit, because it would eliminate the significant costs associated with stapling devices.

To summarize the sealant data, most sealants appear to reduce the percentage of patients with a visible air leak present at the end of an operation. The vast majority of these sealants, however, do not appear to alter duration of air leak or duration of chest tube drainage to a clinically significant degree (and, for the most part, not even to a statistically significant degree). Only 4 of 16 randomized studies showed significantly shortened hospital stays in the sealant group, and only 2 studies clearly showed the reduced air leak and chest tube durations that one might expect to result in this shortened hospital stay. Many of the studies have not report on whether the sealants reduced complicated or prolonged air leak, the outcome variable that is perhaps most important. Finally, only a single study of a liquid sealant applied the product to the group at highest risk, those with substantial emphysema. That study showed a benefit for its sealant (autologous fibrin), giving us a hint that perhaps sealants-like buttresses - might be appropriately applied to selected patients with substantial emphysema.

In light of these inconclusive results across sealant studies and the significantly increased costs that would be incurred by using sealants indiscriminately, it would seem appropriate to use sealants only very selectively at this point. Although our "gut feeling" is that patients with at least moderately severe emphysema undergoing lobectomy may well benefit from the use of sealants on large leaks, such a recommendation has not been securely established by the data.

There remains, then, a substantial need for randomized studies that either evaluate sealants in patients undergoing 
lobectomy who have at least moderate emphysema or are large enough for stratification of results on the basis of degree of emphysema. Similarly, studies large enough for stratification on the basis of the size of the intraoperative air leak would represent substantial contributions, as would more studies that look at prolonged air leak as a primary outcome measure. The most recent data in support of managing incomplete fissures with cautery plus collagen fleece-bound sealants instead of staplers are promising, but the issue requires further study.

\section{OTHER WELL-SUPPORTED TECHNIQUES}

Although a full discussion is beyond the length limitations of this commentary, it must be mentioned that there are 2 traditional techniques of reducing air leaks that have support from prospective, randomized studies in the literature. These include creation of an apical pleural tent after upper lobectomy or upper bilobectomy ( 2 randomized trials with positive results) ${ }^{45,46}$ and creation of pneumoperitoneum after lower bilobectomy (1 randomized trial with positive results). ${ }^{47}$ These techniques are safe and highly effective, and they have essentially zero cost. They are probably underutilized by surgeons.

\section{CONCLUSIONS}

The use of many of the intraoperative techniques that are available to prevent or reduce air leaks has been driven by aggressive marketing by industry of commercially available sealants and staple line buttresses. The appeal of these sealants and buttresses lies in their ease and speed of use. Their costs are sufficiently high, however, that they should be used only if they provide clear clinical benefits.

Buttresses have been shown in randomized trials to reduce the incidence and duration of air leak and to reduce the time that tube drainage is required in patients with severe emphysema undergoing nonanatomic resections. Although the data are not clear for patients with severe emphysema undergoing anatomic lobectomy and segmentectomy, we believe that it is reasonable to use staple-line buttresses in these patients as well.

With regard to liquid sealants, most studies have reported neither statistically nor clinically significant improvements in hospital stay or time to removal of chest tube. Although one might think it logical that sealants would demonstrate clearer benefits in patients with substantial emphysema, this may not be the case, and only a single small study (albeit with positive results) has looked at this subgroup of patients. Also needed are studies that are large enough for stratification on the basis of the size of the initial intraoperative air leaks, more studies that look at prolonged or complicated air leak as an outcome measure, and more studies that evaluate costs. We believe that on the basis of current data, sealants should not be used routinely, and hospitals and insurers may be justified in questioning their use on cost/benefit grounds. The more traditional and relatively cost-free techniques-pleural tenting and pneumoperitoneum-are probably underutilized for high-risk patients.

\section{References}

1. Singhal S, Ferraris VA, Bridges CR, Clough ER, Mitchell JD, Fernando HC, et al. Management of alveolar air leaks after pulmonary resection. Ann Thorac Surg. 2010;89:1327-35

2. Brunelli A, Xiume F, Al Refai M, Salati M, Marasco R, Sabbatini A. Air leaks after lobectomy increase the risk of empyema but not of cardiopulmonary complications: a case-matched analysis. Chest. 2006;130:1150-6.

3. Varela G, Jiménez MF, Novoa N, Aranda JL. Estimating hospital costs attributable to prolonged air leak in pulmonary lobectomy. Eur J Cardiothorac Surg. 2005;27:329-33.

4. Okereke I, Murthy SC, Alster JM, Blackstone EH, Rice TW. Characterization and importance of air leak after lobectomy. Ann Thorac Surg. 2005;79:1167-73.

5. DeCamp MM, Blackstone EH, Naunheim KS, Krasna MJ, Wood DE, Meli YM, et al. Patient and surgical factors influencing air leak after lung volume reduction surgery: lessons learned from the National Emphysema Treatment Trial. Ann Thorac Surg. 2006;82:197-207.

6. Bardell T, Petsikas D. What keeps postpulmonary resection patients in hospital? Can Respir J. 2003;10:86-9.

7. Irshad K, Feldman LS, Chu VF, Dorval JF, Baslaim G, Morin JE. Causes of increased length of hospitalization on a general thoracic surgery service: a prospective observational study. Can J Surg. 2002;45:264-8. Erratum in: Can J Surg. 2003;46:466.

8. Brunelli A, Monteverde M, Borri A, Salati M, Marasco RD, Al Refai M, et al. Comparison of water seal and suction after pulmonary lobectomy: a prospective, randomized trial. Ann Thorac Surg. 2004;77:1932-7.

9. Cerfolio RJ. Chest tube management after pulmonary resection. Chest Surg Clin N Am. 2002;12:507-27.

10. Stolz AJ, Schutzner J, Lischke R, Simonek J, Pafko P. Predictors of prolonged air leak following pulmonary lobectomy. Eur J Cardiothorac Surg. 2005;27: 334-6.

11. Abolhoda A, Liu D, Brooks A, Burt M. Prolonged air leak following radical upper lobectomy: an analysis of incidence and possible risk factors. Chest. 1998;113: 1507-10.

12. Linden PA, Bueno R, Colson YL, Jaklitsch MT, Lukanich J, Mentzer S, et al. Lung resection in patients with preoperative $\mathrm{FEV}_{1}<35 \%$ predicted. Chest. 2005;127:1984-90.

13. Cho MH, Malhotra A, Donahue DM, Wain JC, Harris RS, Karmpaliotis D, et al. Mechanical ventilation and air leaks after lung biopsy for acute respiratory distress syndrome. Ann Thorac Surg. 2006;82:261-6.

14. Cooper JD. Technique to reduce air leaks after resection of emphysematous lung. Ann Thorac Surg. 1994;57:1038-9.

15. Vaughn CC, Wolner E, Dahan M, Grunenwald D, Vaughn CC 3rd, Klepetko W, et al. Prevention of air leaks after pulmonary wedge resection. Ann Thorac Surg. 1997;63:864-6.

16. Shamji MF, Maziak DE, Shamji FM, Matzinger FR, Perkins DG. Surgical staple metalloptysis after apical bullectomy: a reaction to bovine pericardium? Ann Thorac Surg. 2002;74:258-61.

17. Oey I, Waller DA. Metalloptysis: a late complication of lung volume reduction surgery. Ann Thorac Surg. 2001;71:1694-5.

18. Yates DR, Martin-Ucar AE, Vaughan R. Another case of metalloptysis after lung volume reduction surgery. Ann Thorac Surg. 2003;75:636-7; author reply 637.

19. Hazelrigg SR, Boley TM, Naunheim KS, Magee MJ, Lawyer C, Henkle JQ, et al. Effect of bovine pericardial strips on air leak after stapled pulmonary resection. Ann Thorac Surg. 1997;63:1573-5.

20. Stammberger U, Klepetko W, Stamatis G, Hamacher J, Schmid RA, Wisser W, et al. Buttressing the staple line in lung volume reduction surgery: a randomized three-center study. Ann Thorac Surg. 2000;70:1820-5.

21. Miller JI Jr, Landreneau RJ, Wright CE, Santucci TS, Sammons BH. A comparative study of buttressed versus nonbuttressed staple line in pulmonary resections. Ann Thorac Surg. 2001;71:319-23.

22. Venuta F, Rendina EA, De Giacomo T, Flaishman I, Guarino E, Ciccone AM, et al. Technique to reduce air leaks after pulmonary lobectomy. Eur J Cardiothorac Surg. 1998;13:361-4.

23. Belda-Sanchís J, Serra-Mitjans M, Iglesias Sentis M, Rami R. Surgical sealant for preventing air leaks after pulmonary resections in patients with lung cancer. Cochrane Database Syst Rev. 2010;CD003051. 
24. Tambiah J, Rawlins R, Robb D, Treasure T. Can tissue adhesives and glues significantly reduce the incidence and length of postoperative air leaks in patients having lung resections? Interact Cardiovasc Thorac Surg. 2007;6:529-33.

25. Allen MS, Wood DE, Hawkinson RW, Harpole DH, McKenna RJ, Walsh GL, et al. Prospective randomized study evaluating a biodegradable polymeric sealant for sealing intraoperative air leaks that occur during pulmonary resection. Ann Thorac Surg. 2004;77:1792-801.

26. Belboul A, Dernevik L, Aljassim O, Skrbic B, Rådberg G, Roberts D. The effect of autologous fibrin sealant (Vivostat) on morbidity after pulmonary lobectomy: a prospective randomised, blinded study. Eur J Cardiothorac Surg. 2004;26:1187-91.

27. Fabian T, Federico JA, Ponn RB. Fibrin glue in pulmonary resection: a prospective, randomized, blinded study. Ann Thorac Surg. 2003;75:1587-92.

28. Fleisher AG, Evans KG, Nelems B, Finley RJ. Effect of routine fibrin glue use on the duration of air leaks after lobectomy. Ann Thorac Surg. 1990;49:133-4.

29. Lang G, Csekëo A, Stamatis G, Lampl L, Hagman L, Marta GM, et al. Efficacy and safety of topical application of human fibrinogen/thrombin-coated collagen patch (TachoComb) for treatment of air leakage after standard lobectomy. Eur J Cardiothorac Surg. 2004;25:160-6.

30. Macchiarini P, Wain J, Almy S, Dartevelle P. Experimental and clinical evaluation of a new synthetic, absorbable sealant to reduce air leaks in thoracic operations. J Thorac Cardiovasc Surg. 1999;117:751-8.

31. Mouritzen C, Drömer M, Keinecke HO. The effect of fibrin glueing to seal bronchial and alveolar leakages after pulmonary resections and decortications. Eur J Cardiothorac Surg. 1993;7:75-80.

32. Porte HL, Jany T, Akkad R, Conti M, Gillet PA, Guidat A, et al. Randomized controlled trial of a synthetic sealant for preventing alveolar air leaks after lobectomy. Ann Thorac Surg. 2001;71:1618-22.

33. Wain JC, Kaiser LR, Johnstone DW, Yang SC, Wright CD, Friedberg JS, et al. Trial of a novel synthetic sealant in preventing air leaks after lung resection. Ann Thorac Surg. 2001;71:1623-89.

34. Wong K, Goldstraw P. Effect of fibrin glue in the reduction of postthoracotomy alveolar air leak. Ann Thorac Surg. 1997;64:979-81.

35. Wurtz A, Chambon JP, Sobecki L, Batrouni R, Huart JJ, Burnouf T. [Use of a biological glue in partial pulmonary excision surgery. Results of a controlled trial in 50 patients]. Ann Chir. 1991;45:719-23. French.

36. Wurtz A, Gambiez L, Chambon J, Saudemont A. [Evaluation de l'efficacité d'une colle de fibrine en chirurgie d'exérèse pulmonaire partielle. Résultats d'un nouvel essai contrôlé chez 50 malades]. Lyon Chirurgie. 1992;88: 368-71. French.

37. Tansley P, Al-Mulhim F, Lim E, Ladas G, Goldstraw P. A prospective, random ized, controlled trial of the effectiveness of BioGlue in treating alveolar air leaks. J Thorac Cardiovasc Surg. 2006;132:105-12.

38. Droghetti A, Schiavini A, Muriana P, Folloni A, Picarone M, Bonadiman C, et al A prospective randomized trial comparing completion technique of fissures for lobectomy: stapler versus precision dissection and sealant. $J$ Thorac Cardiovasc Surg. 2008;136:383-91.

39. Rena O, Papalia E, Mineo TC, Massera F, Pirondini E, Turello D, et al. Air-leak management after upper lobectomy in patients with fused fissure and chronic obstructive pulmonary disease: a pilot trial comparing sealant and standard treatment. Interact Cardiovasc Thorac Surg. 2009;9:973-7.

40. D'Andrilli A, Andreetti C, Ibrahim M, Ciccone AM, Venuta F, Mansmann U, et al. A prospective randomized study to assess the efficacy of a surgical sealant to treat air leaks in lung surgery. Eur J Cardiothorac Surg. 2009;35:817-21.

41. Moser C, Opitz I, Zhai W, Rousson V, Russi EW, Weder W, et al. Autologous fibrin sealant reduces the incidence of prolonged air leak and duration of chest tube drainage after lung volume reduction surgery: a prospective randomized blinded study. J Thorac Cardiovasc Surg. 2008;136:843-9.

42. Anegg U, Lindenmann J, Matzi V, Smolle J, Maier A, Smolle-Jüttner F. Efficiency of fleece-bound sealing (TachoSil) of air leaks in lung surgery: a prospective randomised trial. Eur J Cardiothorac Surg. 2007;31:198-202.

43. Sackett DL, Rosenberg WM, Gray JA, Haynes RB, Richardson WS. Evidence based medicine: what it is and what it isn't. BMJ. 1996;312:71-2.

44. ACC/AHA Task Force on Practice Guidelines. Methodologies and policies from the ACC/AHA Task Force on Practice Guidelines. Vol 2010. Washington, DC: American Heart Association; 2009.

45. Brunelli A, Al Refai M, Monteverde M, Borri M, Salati M, Sabbatini A, et al Pleural tent after upper lobectomy: a randomized study of efficacy and duration of effect. Ann Thorac Surg. 2002;74:1958-62.

46. Okur E, Kir A, Halezeroglu S, Alpay AL, Atasalihi A. Pleural tenting following upper lobectomies or bilobectomies of the lung to prevent residual air space and prolonged air leak. Eur J Cardiothorac Surg. 2001;20:1012-5.

47. Cerfolio RJ, Holman WL, Katholi CR. Pneumoperitoneum after concomitant resection of the right middle and lower lobes (bilobectomy). Ann Thorac Surg. 2000;70:942-6; discussion, 946-7. 